\title{
The Research and Application of MPPT Technology Based on Combination of Incremental Conductance and Fuzzy Control
}

\author{
Wang Fei \\ School of Electrical Engineering \& Automation, Jiangsu Normal University, \\ Xuzhou 221116, Jiangsu, China \\ wangfeiyanyan@jsnu.edu.cn
}

\begin{abstract}
After discussing analysis of photovoltaic $(P V)$ cell characteristics, and the study of existing PV system maximum power point tracking (MPPT) methods, a MPPT technology based on combination of incremental conductance (INC) and fuzzy control (FC) is proposed to improve the tracking behavior of the single method. The algorithm based on MATLAB 7.6 is developed. The simulation results show that combination algorithm can make the photovoltaic generation system quickly and accurately track the maximum power point (MPP), and its fast response and steady-state performance achieve expectation. Finally, the correctness and effectiveness of the algorithm is verified via power generation statistical data of $P V$ system experimental platform.
\end{abstract}

Keywords: Photovoltaic cell; incremental conductance; fuzzy control; maximum power point tracking (MPPT)

\section{Introduction}

Solar energy often referred to as a clean and renewable energy source, which develops rapidly with the increasing of importance and the decreasing of investment cost in recent years. Nevertheless, many properties of photovoltaic cells has been restricting the rapid development of photovoltaic industry. These characteristics include variable weather factor and inefficiencies in photoelectric transfer [1]. Therefore, it is of great significance to research on the algorithms of MPPT technology of Photovoltaic System (PVS) in order to improve efficiencies in photoelectric transfer.

At present, several kinds of MPPT controlling algorithms have been discussed in many references [2-5]. For instance, there are the constant voltage control method, perturb and observe ( $\mathrm{P} \& \mathrm{O})$ method, incremental-conductance (INC) method and fuzzy control (FC) algorithm and so on. An improved perturbation and observation MPPT method of photovoltaic generating system is described in [3], and the tracking speed is faster than the conventional $\mathrm{P} \& \mathrm{O}$ method. Reference [4] describes the hardware implementation of a real time incremental conductance (INC) MPPT algorithm for a PV module. The experimental results show the proposed method provides a good tracking speed and also mitigation of fluctuation output power. Reference [5] presents a controlling algorithm of MPPT based on the fuzzy algorithm, and the fast tracking performance and the stability of photovoltaic system are improved. Actually, every methods have different advantages and disadvantages.

Such as the incremental-conductance method have good control effect, in particular the better tracking performance following rapidly changing environment. But the control system hardware requirements are relatively high, the system is easy to misjudge, and difficult to select step size. In contrast, fuzzy MPPT control algorithm can well solve the nonlinear problem of power-voltage curve of photovoltaic cells, the better steady state performance, but the response speed of 
system to the outside rapidly changing environment would slow down. Based on these situations, single algorithm does not significantly improve system performance. In reaction to these problems, this paper presents a combination MPPT algorithm of incremental conductance method and fuzzy control method, which tracks fast and does not shock at the maximum power point, greatly improves dynamic and stationary performances.

The structure of the rest of this paper is as follows. In Section 2, analysis of PV cell characteristic is reviewed. The basic principle of incremental conductance and fuzzy control methods are respectively given in Section 3. Proposed combination algorithm is further discussed in Section 4. Modeling and analysis, experimental results and analysis are described in Sections 5 and 6. Conclusions are drawn in Sections 7.

\section{Analysis of PV Cell Characteristic}

\subsection{Equivalent Circuit}

Figure 1 shows the equivalent circuit of a typical PV cell [6].

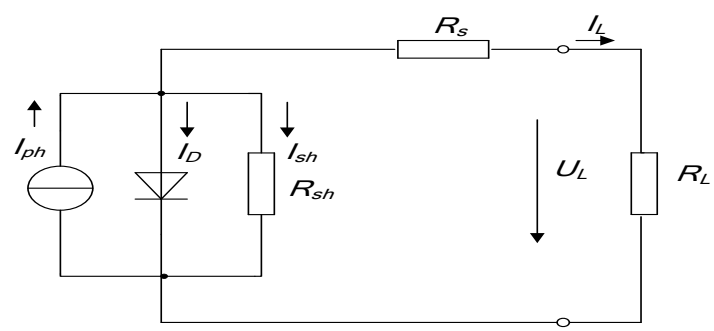

\section{Figure 1. Equivalent Circuit of Photovoltaic Cell}

\subsection{Power characteristics}

The typical IL-UL relationship of a practical PV cell can be described by (1) according to the equivalent circuit of a typical PV cell [7]:

$$
I_{L}=I_{\mathrm{ph}}-A\left\{\exp \left[\frac{\mathrm{q}}{B K T}\left(U_{L}+I_{L} R_{s}\right)\right]-1\right\}-\frac{U_{L}+I_{L} R_{s}}{R_{s h}}
$$

Where $I_{p h}$ denotes light-generated current, $I_{L}$ is PV electric current, $U_{L}$ is PV voltage, A and $\mathrm{B}$ is the material coefficient of PN junction, $k$ is Boltzmann's constant $\left(1.38 \times 10^{-23} \mathrm{~J}\right)$, $T$ is the absolute temperature, $\mathrm{q}$ is the electronic charge $(1.602 \times 10-19 \mathrm{C}), R_{s}$ is the series resistance, and $R_{s h}$ is equivalent bypass resistance.

In this paper, five characteristic parameters $I_{m}, U_{m}, P_{m}, I_{s c}$ and $U_{o c}$ should be extracted from PV cell ( ET-P654200). These parameters are respectively $I_{m}=7.36 \mathrm{~A}, U_{m}=$ $27.21 \mathrm{~V}, P_{m}=200 \mathrm{~W}, I_{s c}=7.86 \mathrm{~A}$ and $U_{o c}=32.72 \mathrm{~V}$, which denotes the current values of maximum power point, the voltage values of maximum power point,, power values of maximum power point, short-circuit current, open-circuit voltage.

Typical Power characteristics of PV cell is affected by many factors, including the two largest factors illumination intensity $(E)$ and environmental temperature $(T)$. Figure 2 plots a set of $P-U$ power curves, which are given from a typical PV cell (ET-P654200) with different illumination intensities and temperatures. As can be seen, there is a complex nonlinear relationship between power output and illumination intensities or temperatures. 


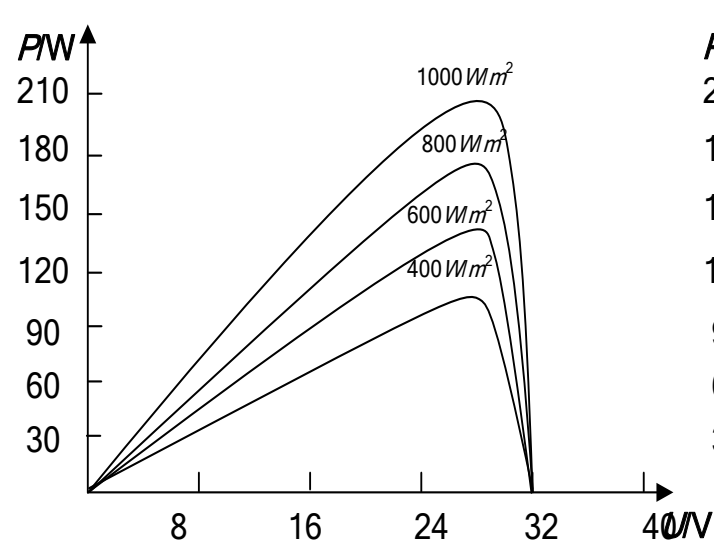

(a)

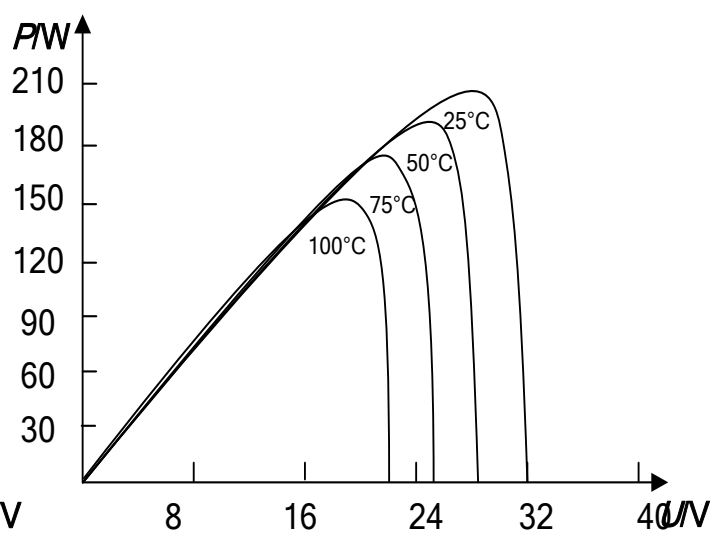

(b)

Figure 2. The Curve of P-U Characteristics of PV Cell with Different Illumination Intensities (a) and Temperatures (b)

\section{Description of INC and FC}

\subsection{Incremental-conductance Method [8]}

The MPP in the PV module occurs when

$$
d P / d U=0
$$

The criteria for the INC MPPT at MPP, differentiated from $P=U I$, can then be given from (2)

$$
\begin{aligned}
& d P / d U=I+U d I / d U \\
& d I / d U=-I / U
\end{aligned}
$$

In difference expression, (4) becomes

$$
\Delta I / \Delta U \approx d I / d U=-I / U
$$

and (5) can also be represented by

$$
\Delta I \cdot U+\Delta U \cdot I=0
$$

Instead of (5), Equation (6) can be applied in algorithm process since the possible uncertainty in (5) may occur in algorithm as $\Delta U \approx 0$.

\subsection{Fuzzy Control Method}

In the photovoltaic power generation system, the fuzzy control can be used to track the maximum power point of photovoltaic [9]. Block diagram of the fuzzy control system is shown in Figure 3. As we see, fuzzy controller plays an important role in fuzzy control system, which mainly includes the following elements:

1) Obtain output variables for controlled objects, compare output variables with reference input, and determine the fuzzy controller input variables.

2) Design the fuzzy control rules of controller.

3) Establish fuzzification method and get fuzzy variables. 
4) Establish defuzzification method and get precise variables.

5) Select the domain of fuzzy input and output variables of fuzzy controller and determine the parameters.

6) Choose a reasonable sampling time and prepare the application of fuzzy control algorithm.

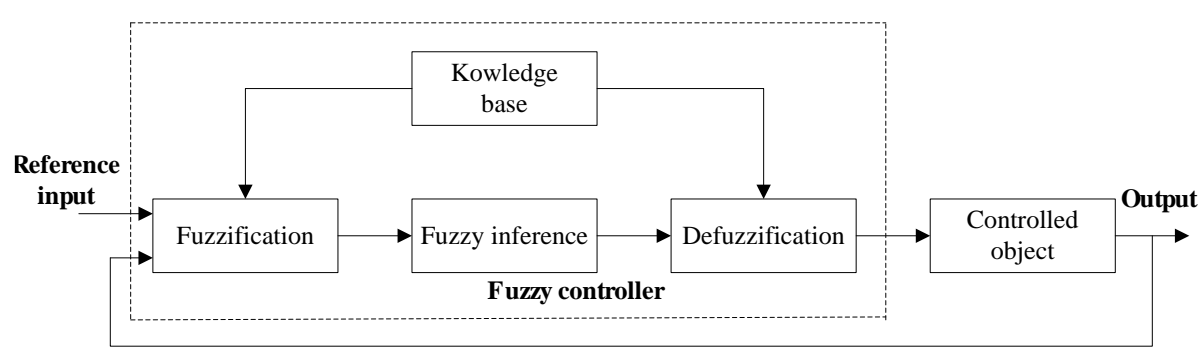

Figure 3. Block Diagram of the Fuzzy Control System

\section{Proposed FC-INC MPPT}

\subsection{The Combination Principle of INC and FC}

The curve of P-U characteristics of PV cell shows that the effect of selected element is most significant. When the points are further from MPP, the cure is steeper. In contrast, the curve gradient is relatively small at the points that are very close to MPP. FC-MPPT is used at the points that are very close to MPP, which require stationary performances higher than that of dynamic performances. On the other hand, INC-MPPT is suitable for the points that are further away from MPP.

\subsection{Establish the Fuzzy controller Variables}

For the purpose of getting the maximum power point tracking, power output of PV cell is used as the objective function. The fuzzy control input is dual input, which are respectively power difference $(d P)$ and increment of duty cycle $(d D n l)$. The fuzzy controller output is provided by the increment of duty cycle of BOOST circuit at this moment $(d D n)$, which is determined by dual input. The variable $d P$ and $d D n$ are expressed as follows:

$$
\begin{aligned}
& d P=P(n)-P(n-1) \\
& d D_{n}=D(n)-D(n-1)
\end{aligned}
$$

Where $P(n)$ and $D(n)$ are the PV array power and duty cycle. Thus, when $d P=0$, the photovoltaic array achieves maximum power point.

Three variables, $d P, d D_{n 1}$ and $d D_{n}$ can be expressed as eight, seven and seven fuzzy subsets, respectively. All the above fuzzy subsets are shown as follows:

$$
\begin{aligned}
\mathrm{dP} & =\{N B, N M, N S, N O, P O, P S, P M, P B\} \\
d D_{n 1} & =d D_{n}=\{N B, N M, N S, Z O, P S, P M, P B\}
\end{aligned}
$$

In algebra expression, the fuzzy subsets are respectively defined as 14, 13 and 13 grades, and as follows:

$$
\begin{gathered}
\mathrm{dP}=\{-6,-5,-4,-3,-2,-1,-0,+0,+1,+2,+3,+4,+5,+6\} \\
d D_{n 1}=d D_{n}=\{-6,-5,-4,-3,-2,-1,0+1,+2,+3,+4,+5,+6\}
\end{gathered}
$$




\subsection{Determine Membership Function}

In this section, the membership functions of three variables are illustrated with triangle in Figure 4.

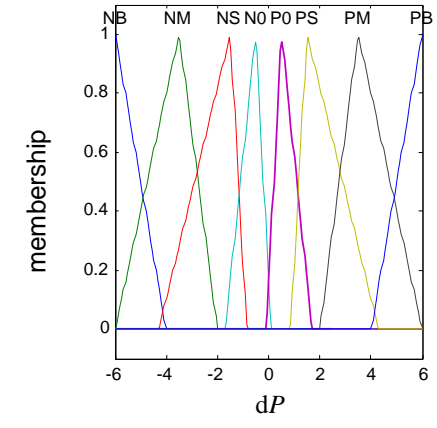

(a)

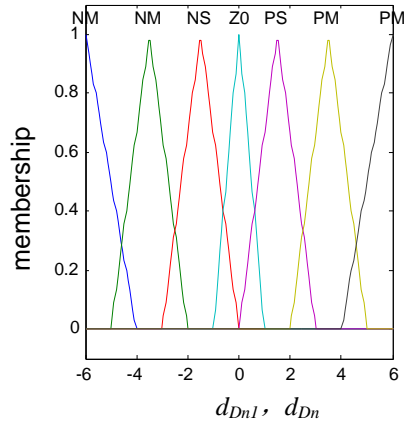

(b)

Figure 4. Membership Functions of $d P(a), d_{D n 1}$ and $d_{D n}(\mathrm{~b})$

\subsection{Design Fuzzy Rules}

To sum up all the fuzzy rules can be drawn from different analysis, as shown in Table 1. The current signal is fuzzy, the gravity method is used in the model for the purpose of getting accurate signals.

Table 1. Rule table of MPPT fuzzy control

\begin{tabular}{ccccccccc}
\hline & \multicolumn{7}{c}{$d_{D n}$} \\
\cline { 2 - 8 }$d_{D n 1}$ & \multicolumn{7}{c}{$\mathrm{d} P$} \\
\cline { 2 - 8 } & NB & NM & NS & NO & PO & PS & PM & PB \\
\hline NB & PB & PM & PS & PS & NS & NS & NM & NB \\
NM & PM & PM & PS & ZO & ZO & NS & NM & NM \\
NS & PS & PS & ZO & ZO & ZO & ZO & NS & NS \\
ZO & PS & ZO & ZO & ZO & ZO & ZO & ZO & NS \\
PS & NS & NS & ZO & ZO & ZO & ZO & PS & PS \\
PM & NM & NM & NS & ZO & ZO & PS & PM & PM \\
PB & NB & NM & NS & NS & PS & PS & PM & PB \\
\hline
\end{tabular}

\section{Modeling and Analysis for FC-INC MPPT}

\subsection{Simulation Model}

Figure 5 shows simulation model that is composed of fuzzy control and incremental conductance with Matlab/Simulink [10,11]. Selection module, its function is select the corresponding algorithm according to PV array power difference. It is switched to fuzzy control when power output is higher than $80 \%$ of the peak power. On the contrary, the incremental conductance method is used in the model. The basic principle of selection module is relatively simple in order to reduce computation complexity. Considering simulation rapidity, INC MPPT module use a fixed step length incremental conductance method with 0.05 duty cycle difference. Fuzzy MPPT module are given the corresponding parameter based on stability requirements, including quantifying factor $k_{P}=10$, scaling factor $k_{D}=0.01$. 


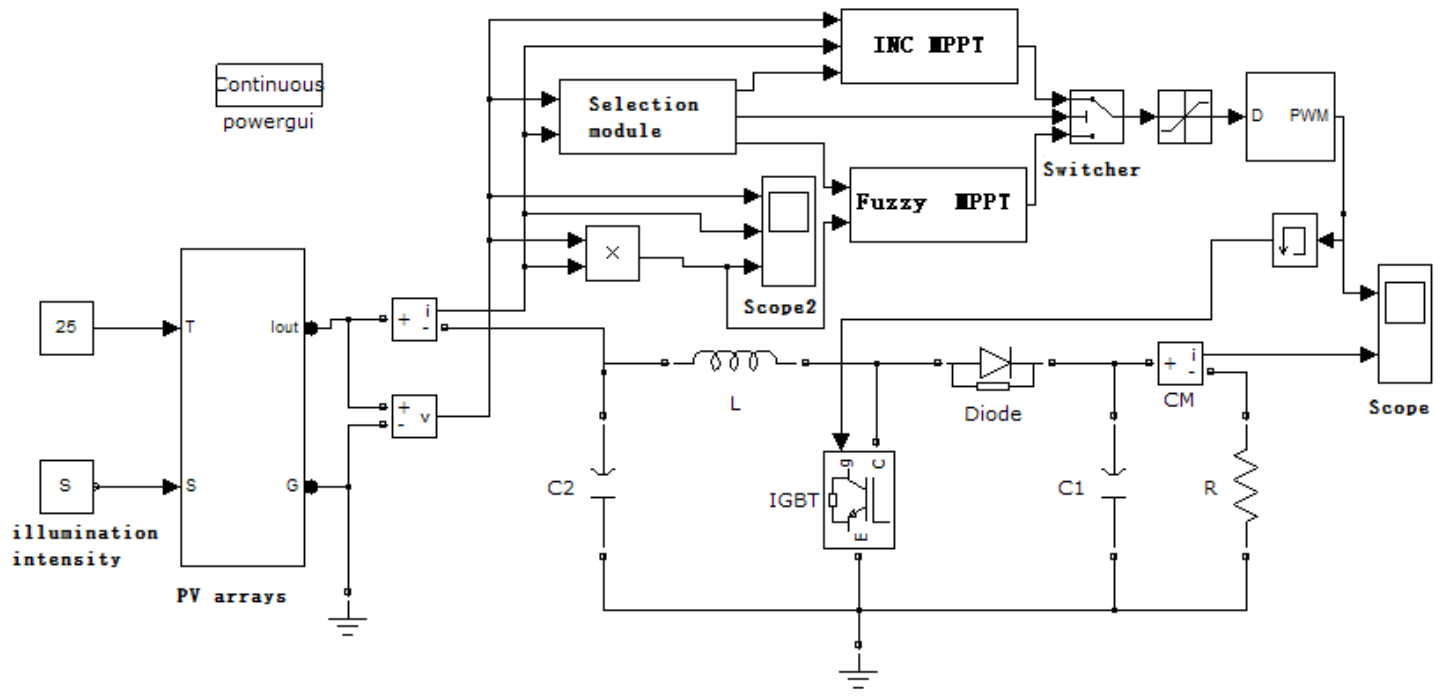
Figure 5. MPPT Simulation Model of the Combination of Incremental
Conductance and Fuzzy Control

\subsection{Simulation Results and Analysis}

By comparing four algorithm, including INC, FC, P\&O and FC-INC, simulation results of four algorithms are shown in Figure 6. Simulation parameters include ode23tb simulation algorithm, $1 \mathrm{~s}$ simulation time, $0.001 \mathrm{~s}$ sample period, $25^{\circ} \mathrm{C} \mathrm{PV}$ array temperature. The illumination intensity is assumed suddenly from $800 \mathrm{~W} / \mathrm{m} 2$ to 1000 $\mathrm{W} / \mathrm{m} 2$ in $0.5 \mathrm{~s}$. As can be seen, Figure 6 (a) show it is difficult to achieve a steady state at nearby MPP with INC MPPT algorithm. Similarly, Figure 6 (b) show oscillation phenomenon at very close to MPP with $\mathrm{P} \& \mathrm{O}$ MPPT algorithm. The oscillation phenomenon is improved significantly in Figure 6 (c) when using FC MPPT algorithm, but the response speed of system would slow down by comparing the former algorithm. Figure 6 (d) shows simulation curves of FC-INC MPPT algorithm, which is able to quickly reach a steady state with low- oscillation and fast-response.

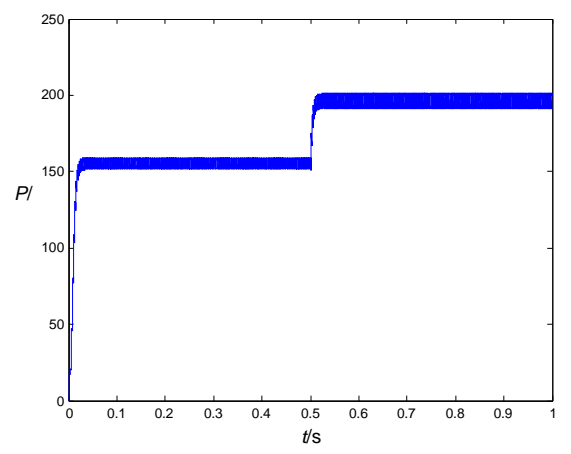

(a)

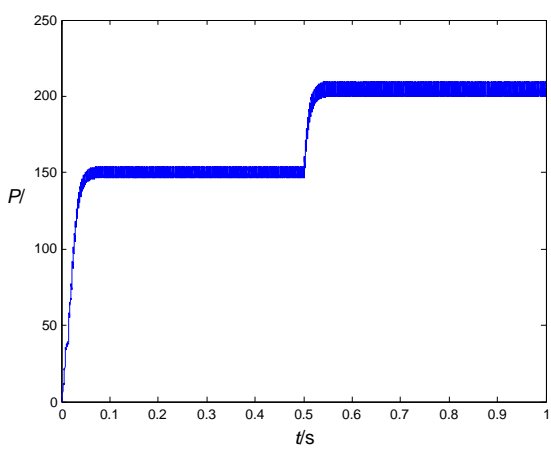

(b) 


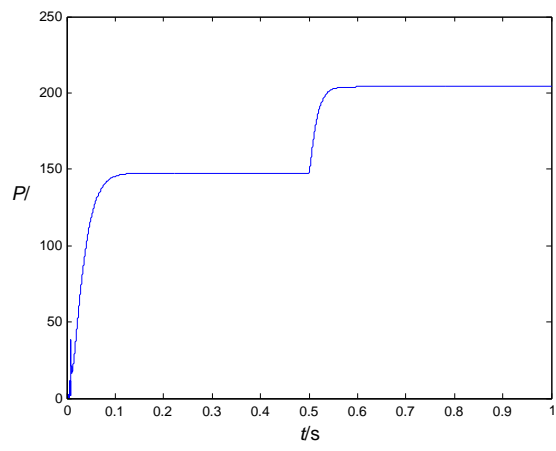

(c)

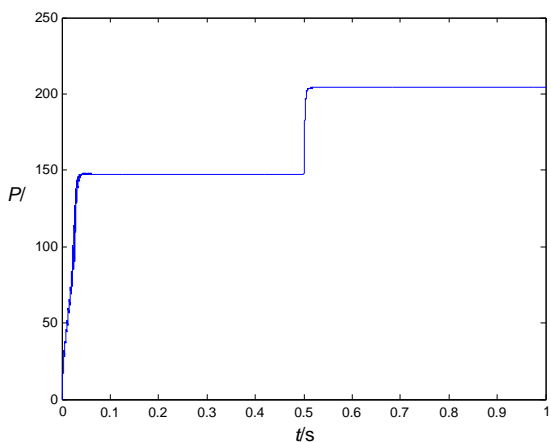

(d)

Figure 6. MPPT Simulation Result of Incremental Conductance Method (a, Perturbation and Observation Method (b), Fuzzy Control Method (c), and the Combination Method d)

\section{Experimental Results and Analysis}

PV system structure diagram and PV system experimental platform, respectively, displayed in Figure 7 and Figure 8. 2kW PV system experimental platform is used to verify the correctness and effectiveness of the combination algorithm. Experimental platform include $10 \mathrm{PV}$ arrays (ET-P654200), peak power of every PV array is $200 \mathrm{~W}$. The controller is based on embedded DSP - TMS 320 LF 2407.

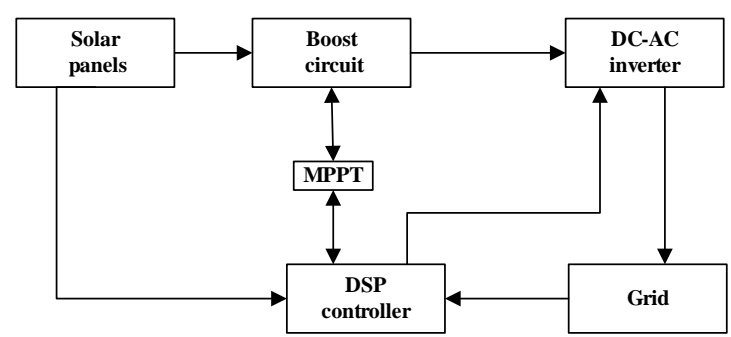

Figure 7. PV System Structure Diagram

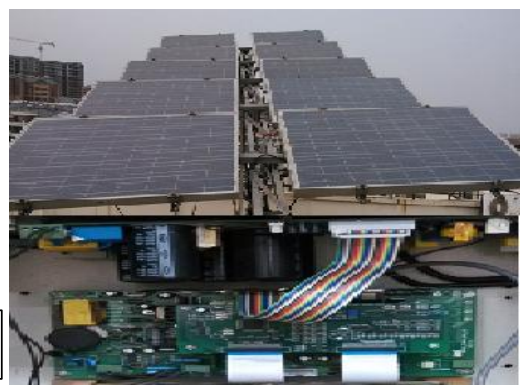

Figure 8. PV System Experimental Platform

According to experimental statistics, power generation of three MPPT methods are shown in Table 2. By comparing statistics, power generation of combination method is more than using single method, either INC method or FC method. The first quarter is used as an example for this discussion. Here, power generation of combination method is 489.1 $\mathrm{kWh}$, which is $45.6 \mathrm{kWh}$ more than INC method, and $29.6 \mathrm{kWh}$ more than FC method.

\section{Table 2. Power Generation Statistical Table of Three MPPT Methods}

\begin{tabular}{ccccc}
\hline \multirow{2}{*}{ Generation $(\mathrm{kWh})$} & \multicolumn{4}{c}{ Statistical period } \\
\cline { 2 - 5 } & quarter & $\begin{array}{c}\text { The second } \\
\text { quarter }\end{array}$ & $\begin{array}{c}\text { The third } \\
\text { quarter }\end{array}$ & $\begin{array}{c}\text { The fourth } \\
\text { quarter }\end{array}$ \\
\hline $\begin{array}{c}\text { INC method } \\
\text { the year 2013) }\end{array}$ & 450.8 & 554.9 & 608.2 & 433.5 \\
$\begin{array}{c}\text { FC method } \\
\text { the year 2011) } \\
\text { combination method } \\
\text { (the year 2012) }\end{array}$ & 460.7 & 574.4 & 620.6 & 439.2 \\
\hline
\end{tabular}




\section{Conclusion}

In this paper, MPPT technology based on combination of incremental conductance and fuzzy control is used in PV system, which makes full use of INC MPPT method's fast-response and FC method's low-oscillation and has passed experimental verification. This combination method can make PV array working at maximum power point more quickly and accurately than single algorithm does. System performance is improved significantly when the combination method is used in the model. Therefore, it would be better method for MPPT.

\section{Acknowledgement}

The author greatly thanks the editor and the reviewers for their valuable comments and suggestions. This study was supported by Scientific Research Foundation of Jiangsu Normal University (NO.11XLA18).

\section{Conflicts of Interest}

The authors declare that there is no conflict of interests.

\section{References}

[1] W. Zghal, G. Kantchev, and H. Kchaou, "Determination of the exploitable solar energy for electricity generation using the photovoltaic systems", 2012 1st International conference on Renewable Energies and Vehicular Technology, (2012) March 26-28, Nabeul, Tunisia.

[2] M. A. Eltawil and Z. M. Zhao, "MPPT techniques for photovoltaic applications", Renewable and Sustainable Energy Reviews, vol. 25, (2013).

[3] N. Femia, D. Granozio, G. Predictive, G. Spagnuolo and M. Vitelli, "Predictive \& adaptive MPPT perturb and observe method", IEEE Transactions on Aerospace and Electronic Systems, vol. 3, no. 43, (2007).

[4] R. Faraji, A. Rouholamini, H. R. Naji, R. Fadaeinedjad and M. R. Chavoshian, "FPGA-based real time incremental conductance maximum power point tracking controller for photovoltaic systems", IET Power Electronics, vol. 5, no. 7, (2014).

[5] Z. D. Wu and X. W. Wang, "A photovoltaic MPPT fuzzy controlling algorithm”, Taiyangneng Xuebao, vol. 6, no. 32, (2011).

[6] H. Park, and H. Kim, "PV cell modeling on single-diode equivalent circuit", Industrial Electronics Conference, (2013) November 10-14; Vienna, Austria.

[7] H. M. Tian, D. M. Fernando, K. Ellis, E. Muljadi and P. Jenkins, "A cell-to-module-to-array detailed model for photovoltaic panels", Solar Energy, vol. 9, no. 86, (2012).

[8] K. Y. Huang, W. S. Li and X. Y. Huang, "MPPT of solar energy generating system with fuzzy control and artificial neural Network", Proceedings of the 2011 International Conference of Information Technology, Computer Engineering and Management Sciences, (2011) September 24-25; Nanjing, Jiangsu, China.

[9] Z. Cheng, H. Z. Yang and Y. Sun, "FPGA-based PV systems fuzzy MPPT control algorithm", Proceedings of the 7th International Conference on Fuzzy Systems and Knowledge Discovery, (2010) August 10-12; Yantai, Shandong, China.

[10] A. Barchowsky, J. P. Parvin, G. F. Reed, M. J. Korytowski and B. M. Grainger, "A comparative study of MPPT methods for distributed photovoltaic generation", 2012 IEEE PES Innovative Smart Grid Technologies, (2012) January 16-20; Washington, DC, United states.

[11] G. C. Hsieh, H. I. Hsieh, C. Y. Tsai and C. H. Wang, "Photovoltaic power-increment-aided incremental-conductance MPPT with two-phased tracking", IEEE Transactions on power electronics, vol. 6 , no. $28,(\mathbf{2 0 1 3})$. 